\title{
Spatial assessment of potential ecological risk of heavy metals in soils from informal e-waste recycling in Ghana
}

\author{
Vincent Nartey Kyere ${ }^{1}$, Klaus Greve 2 , Sampson Manukure Atiemo ${ }^{3}$, James Ephraim ${ }^{4}$ \\ ${ }^{1}$ Departmrnt of Ecology and Natural Resources, Center for Development Research, University of Bonn, Bonn, Germany; \\ ${ }^{2}$ Geography Institute, University of Bonn, Bonn, Germany; ${ }^{3}$ Ghana Atomic Energy Commission, Accra, Ghana; ${ }^{4}$ Nduom \\ University College, Elmina, Ghana
}

The rapidly increasing annual global volume of e-waste, and of its inherently valuable fraction, has created an opportunity for individuals in Agbogbloshie, Accra, Ghana to make a living by using unconventional, uncontrolled, primitive and crude procedures to recycle and recover valuable metals from this waste. The current form of recycling procedures releases hazardous fractions, such as heavy metals, into the soil, posing a significant risk to the environment and human health. Using a handheld global positioning system, 132 soil samples based on $100 \mathrm{~m}$ grid intervals were collected and analysed for cadmium (Cd), chromium (Cr), copper $(\mathrm{Cu})$, mercury $(\mathrm{Hg})$, lead $(\mathrm{Pb})$ and zinc $(\mathrm{Zn})$. Using geostatistical techniques and sediment quality guidelines, this research seeks to assess the potential risk these heavy metals posed to the proposed Korle Ecological Restoration Zone by informal e-waste processing site in Agbogbloshie, Accra, Ghana. Analysis of heavy metals revealed concentrations exceeded the regulatory limits of both Dutch and Canadian soil quality and guidance values, and that the ecological risk posed by the heavy metals extended beyond the main burning and dismantling sites of the informal recyclers to the school, residential, recreational, clinic, farm and worship areas. The heavy metals $\mathrm{Cr}, \mathrm{Cu}, \mathrm{Pb}$ and $\mathrm{Zn}$ had normal distribution, spatial variability, and spatial autocorrelation. Further analysis revealed the decreasing order of toxicity, $\mathrm{Hg}>\mathrm{Cd}>\mathrm{Pb}>$ $\mathrm{Cu}>\mathrm{Zn}>\mathrm{Cr}$, of contributing significantly to the potential ecological risk in the study area.
Correspondence: Vincent Nartey Kyere Department of Ecology and Natural Resources, Center for Development Research, University of Bonn, Walter Flex Strasse, Bonn 53113, Germany

E-mail: kyerevincent@gmail.com

Received: March 31, 2017

Accepted: September 30, 2017

Published: October 17, 2017

This article is available from: http://e-eht.org/

Keywords E-waste, Heavy metals, Geostatistics, Ecological risk, Ghana

\section{INTRODUCTION}

Crude and primitive methods of recycling e-waste, such as burning and manual dismantling, are a major source of heavy metals in the environment [1-3]. Heavy metal contamination is one of the serious threats to the environment, as it has the potential to contaminate or pollute the environment or vicinity in which it occurs. Further, with the potential of heavy metals to disperse and accumulate in the soil and be taken up by plants, animals and human, heavy metals pose significant ecological and human health risks [4]. The increasing volume of electrical and electronic waste as a result of both locally generated end-oflife electrical and electronic equipment (EEE) and imported end-of-life under the disguise of second hand, slightly used or charity EEE, has created an opportunity for individuals in an unregulated informal e-waste recycling sector, where crude, rude and unconventional processes are used to recover valuable and precious metals from discarded EEE. Agbogbloshie, located in Ghana's national capital, is notorious for its crude and primitive recycling methods, such open burning and manual dismantling, for the recovery of valuable fractions of discarded EEE. The operations of workers in Agbogbloshie not only leaves a 
footprint of heavy metals, polychlorinated biphenyl, and brominated flame retardants, but pose significant risks to the environment and to human health.

Earmarked since 2003 by the Ghanaian government to restore Agbogbloshie through the Korle Lagoon Ecological Restoration Project, the continuous operations of informal e-waste recyclers will leave behind deposits and accumulation of heavy metals in the soil that will be difficult and costly to remediate. Again, there is the possibility of significant amounts of heavy metals being washed or discharged into rivers, subsequently being accumulated in the water sediment, and the aquatic food chain, which can have toxic or hazardous implications for aquatic species $[5,6]$. With bottom and surface sediments providing habitats and also serving as a food source for all kinds of species, heavy metal contaminants could directly or indirectly pollute or contaminate aquatic flora and fauna, which might also be reflected on land as a result of bioaccumulation in the food web [7]. Further, heavy metals can accumulate in dust from atmospheric deposition by sedimentation interception, and could impact the health of people if they accumulate levels of these pollutants regarded as toxic $[8,9]$. It was suggested that this health risk is especially high for children because of their low tolerance to pollutants or contaminates as well as the inadvertent ingestion of significant quantities of dust (or soil) through hand-to-mouth pathways. Although several studies $[1,2,10-12]$ in Ghana have measured significant amount of heavy metals from the Agbogbloshie e-waste processing site (AEPS), little is known about the ecological and human health risks posed by the release of heavy metals from the recycling of e-waste in Agbogbloshie. The potential risk posed to the environment by heavy metal pollutants has been studied [57,13-15], however little is known of its ecological risk in Ghana.

The purposes of this study are: (1) to assess the risk posed to the environment by heavy metals using numerical sediment quality guidelines that represent the thresholds of chemical concentrations associated with the presence or absence of biological effects on communities and ecological risk factors defined by Hakanson [6], (2) to examine the spatial extent of the potential ecological risk. AEPS is known to be polluted by various heavy metals $[2,3,10]$, but there is limited or no information on the ecological risk of these heavy metals, this study seeks to fill that gap.

\section{METHODS}

\section{Study Area}

The study area, Agbogbloshie, is located close to the central business district of Ghana's national capital. Situated at the heart of this community or area is the AEPS where recyclers use primitive recycling methods, such as open burning, simple tools, such as hammers, chisels and stones, to recover valuable fractions of discarded EEE. The Agbogbloshie site is situated on a bank of the Odaw River and in the upper reaches of the Korle Lagoon. Within the Agbogbloshie are the main burning and dismantling sites, a school, a commercial area (CA), clinics, residences, recreational areas, farms, and two houses worship premises.

\section{Data Collection and Laboratory Analysis}

Using a grid based sampling procedure with $100 \mathrm{~m}$ intervals, 132 samples were collected from the AEPS. The collected samples were air dried at room temperature, and then sieved using a $100 \mu \mathrm{m}$ mesh. The samples were pulverized into a $2.5 \mathrm{~cm}$ diameter thick pellet, which was compressed using a 10 ton hydraulic press. Using acid tone or nitric acid and wool, the equipment was cleaned after each procedure so as to avoid cross contamination. The analysis of the heavy metal concentrations in the prepared samples was done using an X-ray fluorescence (XRF) spectrometer (Skyray Instrument, Stoughton, MA, USA) at a maximum power of $3000 \mathrm{~W}(60 \mathrm{kV}$ and $50 \mathrm{~mA})$. The pelleted samples were placed in a disk and then placed on the excitation source of the XRF for a 10-minute irradiation using a silicon $(\mathrm{Si})$ lithium detector with a resolution of $16 \mathrm{~V}$ with manganese and $\mathrm{Ka}$ peak used throughout the procedure. To validate the procedure and ensure quality control, International Atomic Energy Agency (IAEA) standard reference IAEA soil 7 was irradiated 5 times and the average values compared with the recommended values before the analysis of the prepared samples.

\section{Data Analysis}

Exploratory data analysis for descriptive characteristics such as the mean, median, standard deviation, skewness and coefficient of variation was performed in $\mathrm{R}$ version 3.2.1 (Comprehensive RArchive Network: http://cran.r-project.org).

\section{Enrichment Factor}

The enrichment factor (EF) as applied and expressed in equation (1) was used to differentiate between metals originating from human activities and those of natural or non-anthropogenic influence within AEPS $[16,17]$. The study adopted the EF method for assessing potential contamination, as the method has been shown to be reliable, provided the elemental contents are corrected following a careful normalization procedure and the reference sediment is not affected by diagenetic alterations.

$$
E F=\frac{\left(C_{n} / C_{\text {ref }}\right) \text { sample }}{\left(B_{n} / B_{\text {ref }}\right) \text { reference }}
$$

Here, $C_{n}$ is the concentration of the investigated heavy metal in the study area, $C_{\text {ref }}$ is the background concentration (crust aver- 
age) of the investigated metal, $B_{n}$ is the concentration of the reference heavy metal, and $B_{\text {ref }}$ is the background concentration of the reference heavy metal. The EF defines the following criteria: $<2$, deficiency to minimal; $2 \leq \mathrm{EF}<5$, moderate; $5 \leq \mathrm{EF}<20$, significant; $20 \leq \mathrm{EF}<40$, very high; and $\mathrm{EF}>40$, extremely high. Although a local preindustrial background reference is preferred to continental crust averages, as it enables a realistic comparison to be made between pristine sediment contamination or a lower core with similar but contaminated sediment or upper layers [18], and also due to textural, mineralogical and bulk chemical similarity between the compared sediment samples, nevertheless the continental crust averages were used here due to the difficulty in identifying an uncontaminated site, as the historical background of activities that have taken place in the identified uncontaminated site or lower core of soil sediment must be taken into consideration. The study used $\mathrm{Si}$ as the normalizing or reference metal as it is considered as an acceptable normalization element in the calculation of the EF. Si was used as it is not related to the other heavy metals under investigation and also has a relatively high natural concentration in soil and is not expected to be enriched substantially from anthropogenic sources at the AEPS.

\section{Ecological RiskAssessment}

The potential ecological risk index (RI) was originally used to assess the degree of heavy metal pollution in the soil and is based on the toxicity of the heavy metal and the toxicity response of the environment [6]. The RI is given by:

$$
\mathrm{RI}=\Sigma_{i-1}^{n} E_{r}^{i}
$$

Here, RI is defined by the following: $<150$, low; $150-300$, moderate; 300-600, high; and $\geq 600$, significantly [19].

$$
E_{r}^{i}=T_{r}^{i} \times C_{r}^{i}
$$

Where $E_{r}^{i}$ is defined as the ecological risk factor and $T_{r}^{i}$ is defined as the toxic response factor provided by Hakanson [6].
$E_{r}^{i}$ defines the following criteria: $<40$, low; 40-80, moderate; 80160 , considerable; $160-320$, high; and $\geq 320$, significantly high.

\section{GeostatisticalAnalysis}

Geostatistical analysis based on the theory of a regionalized variable with spatial coordinates and with spatial autocorrelation explains that samples close together in space are more alike than those that are further apart [20]. In this study, variogram techniques in ArcGIS version 10.4 (ESRI Inc., Redlands, CA, USA) were used to examine the spatial variability of the regionalized variable and also provide input parameters of sill, nugget and range for the spatial interpolation [21]. Spatial autocorrelation, which measures the degree to which the spatial variable (heavy metals) and their associated values tend to be clustered together in space, was assessed using the global Moran index (MI) expressed by equation (4).

$$
\mathrm{MI}=\frac{N \Sigma_{i=1}^{n} \sum_{j=1}^{n} W_{i j}\left(x_{i}-\bar{x}\right)\left(x_{j}-\bar{x}\right)}{\left(\sum_{i=1}^{n} \sum_{j=1}^{n} W_{i j}\right) \Sigma_{i=1}^{n}\left(x_{i}-\bar{x}\right)}
$$

Where $\mathrm{N}$ is the number of observations, $x$ is the mean of the variable (heavy metal or potential ecological $\mathrm{RI}$ ), $x_{i}$ is the value at a particular location of the variable, $x_{j}$ is its value at another location, and $W_{i j}$ is a weighting of location $i$ relative to $j$. The MI evaluates whether the pattern expressed is clustered, dispersed, or random, and uses both a $Z$-score and $p$-value in evaluating the significance of that index and the null hypothesis that there is no spatial clustering of the values associated with the geographic features in the study area. The measure and depiction of spatial variability in the geostatistical analysis was conducted using the technique of the variogram (or semi-variogram), which also provided the input parameters for the spatial interpolation of kriging. Ordinary kriging was used for the interpolation after a best fit model was identified.

\section{RESULTS}

\section{Descriptive Statistics}

\begin{tabular}{|c|c|c|c|c|c|c|c|c|c|c|}
\hline \multirow{2}{*}{ Heavy metal } & \multirow{2}{*}{ Mean } & \multirow{2}{*}{ Median } & \multirow{2}{*}{ Min } & \multirow{2}{*}{ Max } & \multirow{2}{*}{ SD } & \multirow{2}{*}{ CV } & \multirow{2}{*}{ Skewness } & \multicolumn{2}{|c|}{ Dutch SQGV } & \multirow{2}{*}{$\begin{array}{c}\text { Canadian } \\
\text { SQGV }\end{array}$} \\
\hline & & & & & & & & Optimal & Action & \\
\hline $\mathrm{Cd}$ & 6.56 & 3.85 & 0.40 & 26.50 & 6.84 & 1.04 & 1.35 & 0.8 & 12 & 10 \\
\hline $\mathrm{Cr}$ & 296.60 & 197.30 & 21.10 & 1332.00 & 273.26 & 0.92 & 1.57 & 100.0 & 380 & 64 \\
\hline $\mathrm{Cu}$ & 1387.96 & 290.65 & 9.40 & 18285.00 & 2507.19 & 1.81 & 3.70 & 36.0 & 190 & 63 \\
\hline $\mathrm{Hg}$ & 2.70 & 1.40 & 0.40 & 13.40 & 2.89 & 1.07 & 2.03 & 0.2 & 10 & 7 \\
\hline $\mathrm{Pb}$ & 953.21 & 290.95 & 14.20 & 10280.00 & 1734.84 & 1.82 & 3.29 & 85.0 & 530 & 140 \\
\hline $\mathrm{Zn}$ & 1371.14 & 576.55 & 41.90 & 12907.50 & 1923.75 & 1.40 & 3.07 & 140.0 & 720 & 200 \\
\hline
\end{tabular}

The descriptive analysis of cadmium (Cd), chromium (Cr),

Table 1. Summary statistics of heavy metal concentrations from Agbogbloshie e-waste processing site (unit: ppm)

ppm, parts per million; Min, Minimum; Max, Maximum; SD, standard deviation; CV, coefficient of variation; SQGV, soil quality and guidance values; Cd, cadmium; Cr, chromium; Cu, copper; Hg, mercury; Pb, lead; Zn, zinc. 
copper $(\mathrm{Cu})$, mercury $(\mathrm{Hg})$, lead $(\mathrm{Pb})$, and zinc $(\mathrm{Zn})$ used in the assessment of the potential ecological risk are presented in Table 1. The kurtosis (a measure used to describe the normality of a distribution) and skewness for $\mathrm{Cd}, \mathrm{Cr}$ and $\mathrm{Hg}$ were relatively low (Table 1). However, for $\mathrm{Cu}, \mathrm{Pb}$ and $\mathrm{Zn}$, they were high, which indicates a non-normality of the distributions for these heavy metals. The significant differences between the mean and the median of all heavy metals also prove that they were not normally distributed. Furthermore, the coefficients of variation of $\mathrm{Pb}, \mathrm{Cu}$ and $\mathrm{Zn}$ were 1.82, 1.81 and 1.40, respectively, and higher than those of $\mathrm{Cr}, \mathrm{Cd}$ and $\mathrm{Hg}$, suggesting that the former had greater variation among the soils in the study area.

\section{Enrichment Factor}

The results of the EF for the investigated heavy metals are pre-

Table 2. Enrichment factors of heavy metals by site (unit: ppm)

\begin{tabular}{lrrrrrr}
\hline Site & $\mathrm{Cd}$ & $\mathrm{Cr}$ & $\mathrm{Cu}$ & $\mathrm{Hg}$ & $\mathrm{Pb}$ & \multicolumn{1}{c}{$\mathrm{Zn}$} \\
\hline Burning & 78.25 & 2.66 & 83.61 & 67.21 & 330.51 & 41.77 \\
CA & 3.68 & 3.46 & 3.41 & 5.20 & 15.59 & 8.77 \\
Clinic & 0.00 & 1.32 & 0.82 & 0.00 & 4.94 & 3.49 \\
Dismantling & 56.07 & 6.02 & 42.91 & 28.54 & 97.28 & 39.78 \\
Farm & 1.14 & 4.05 & 2.11 & 7.92 & 14.55 & 4.91 \\
Recreational & 11.18 & 4.05 & 16.59 & 7.78 & 33.99 & 11.97 \\
Residential & 19.71 & 2.31 & 36.91 & 30.73 & 107.44 & 25.06 \\
School & 1.27 & 1.20 & 0.88 & 6.96 & 9.02 & 4.24 \\
Worship & 1.57 & 1.93 & 2.25 & 5.62 & 9.78 & 6.27 \\
\hline
\end{tabular}

ppm, parts per million; $\mathrm{Cd}$, cadmium; $\mathrm{Cr}$, chromium; $\mathrm{Cu}$, copper; $\mathrm{Hg}$, mercury; $\mathrm{Pb}$, lead; Zn, zinc; CA, commercial area. sented in Table 2. The results indicate that the EFs for all the heavy metals apart from $\mathrm{Cr}$ were highest and considered extremely high enrichment in the burning and dismantling sites indicating the influence of anthropogenic activities of e-waste recycling as the source of the heavy metals $\mathrm{Cd}, \mathrm{Cu}, \mathrm{Hg}, \mathrm{Pb}$ and $\mathrm{Zn}$ in the soil. Also worth noting in Table 2 are the EFs of the heavy metals in the residential and recreational areas within the AEPS, where in the recreational area $\mathrm{Cr}<\mathrm{Hg}<\mathrm{Cd}<\mathrm{Zn}<\mathrm{Cu}<\mathrm{Pb}$ order showed an increasing $\mathrm{EF}$ which ranges from deficiency to very high enrichment. A similar trend in the order of the $\mathrm{EF}$ is also seen in the residential area, with $\mathrm{Cd}$ and $\mathrm{Hg}$ alternating.

\section{Ecological Risk Factors}

With AEPS earmarked for an ecological restoration zone, the ecological risk factor for each heavy metal under investigation as well as the overall potential ecological risk were calculated using equations (2) and (3). The purpose of the assessment is to provide an empirical basis for understanding the ecological risks associated with these heavy metal concentrations in the soils in the AEPS. The assessment was conducted based on six heavy metals where the toxicity response factor is provided by Hakanson [6]. Table 3 lists the summary statistics of the ecological risk factors.

The mean and maximum $\mathrm{Zn}$ values show a "low ecological risk", as the factors are all below 40 , however, the maximum value indicates moderate ecological risk. The mean and maximum ecological risks for $\mathrm{Cd}, \mathrm{Hg}$ and $\mathrm{Pb}$ are significantly high with a value above 320 .

Table 3. Summary statistics of ecological risk factors (unit: ppm)

\begin{tabular}{|c|c|c|c|c|c|c|c|c|}
\hline Heavy metal & Mean & Median & SD & Min & Max & CV & Skewness & Kurtosis \\
\hline $\mathrm{Cd}$ & 984.02 & 577.50 & 1026.14 & 60.00 & 3975.00 & 1.04 & 1.35 & 1.02 \\
\hline $\mathrm{Cr}$ & 5.88 & 3.95 & 5.27 & 0.42 & 21.98 & 0.90 & 1.40 & 1.24 \\
\hline $\mathrm{Cu}$ & 115.56 & 26.42 & 176.66 & 0.82 & 750.36 & 1.53 & 2.20 & 4.56 \\
\hline $\mathrm{Hg}$ & 1304.58 & 700.00 & 1297.11 & 200.00 & 4950.00 & 0.99 & 1.63 & 1.70 \\
\hline $\mathrm{Pb}$ & 351.24 & 116.38 & 568.33 & 5.68 & 2361.20 & 1.62 & 2.63 & 6.39 \\
\hline $\mathrm{Zn}$ & 17.85 & 8.24 & 20.51 & 0.60 & 77.11 & 1.15 & 1.60 & 1.76 \\
\hline
\end{tabular}

ppm, parts per million; SD, standard deviation; Min, Minimum; Max, Maximum; CV, coefficient of variation; Cd, cadmium; Cr, chromium; Cu, copper; Hg, mercury; Pb, lead; Zn, zinc.

Table 4. Summary statistics and geostatistical parameters of potential ecological risk index

\begin{tabular}{|c|c|c|c|c|c|c|c|c|}
\hline & & & mination as & ment & & & & \\
\hline \multirow[t]{2}{*}{ Summary statistics } & Mean & Median & SD & Minimum & Maximum & CV & Skewness & Kurtosis \\
\hline & 1892.67 & 694.57 & 2774.86 & 8.04 & 12122.46 & 1.46 & 2.01 & 3.47 \\
\hline \multirow[t]{2}{*}{ Spatial autocorrelation } & $\mathrm{Ml}$ & EV & Variance & Z-score & $p$-value & DT & & \\
\hline & 0.168 & -0.008 & 0.006 & 2.277 & 0.02 & 500 & & \\
\hline \multirow[t]{5}{*}{ Geostatistical characteristics } & Model & Nugget (Co) & Sill (C1) & $\mathrm{Co} / \mathrm{C} 1$ & Range & & & \\
\hline & Spherical & 0.20 & 0.83 & 0.24 & 719.47 & & & \\
\hline & Exponential & 0.17 & 0.92 & 0.19 & 1099.54 & & & \\
\hline & Gaussian & 0.28 & 0.69 & 0.41 & 495.46 & & & \\
\hline & K-Bessel & 0.27 & 0.70 & 0.39 & 518.78 & & & \\
\hline
\end{tabular}

SD, standard deviation; Min, minimum, Max, maximum; CV, coefficient of variation; MI, Moran index; EV, error variance; DT, distance threshold. 


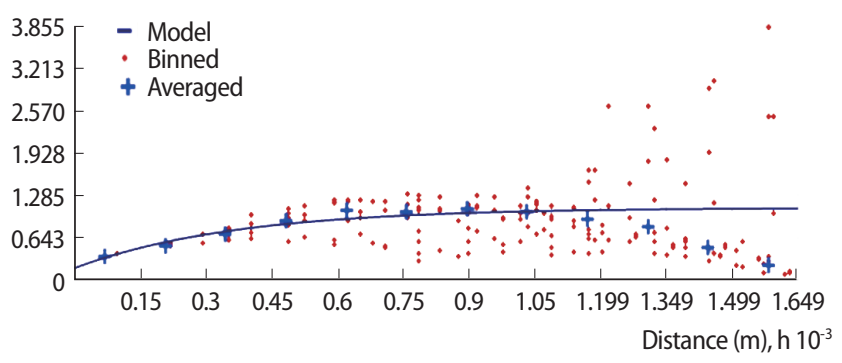

Figure 1. Semivariogram fitted with exponential model for potential ecological risk Index.

\section{Spatial Structure of Potential Ecological Risk Index}

Table 4 shows the summary statistics and geostatistical parameters of the potential ecological RI. The skewness, kurtosis, and the significant difference between the mean and the median, indicate that the ecological RI is not normally distributed. The Gaussian kernel normal score transformation shows that the ecological RI is spatially autocorrelated with a MI at a Z-score of 2.277 and $p$-value of 0.02 at a threshold distance of $500 \mathrm{~m}$, indicating possible spatial randomness in the data. Of the 4 models used to test for the best fit of the isotropic model of the potential ecological RI, a strong spatial dependency in the order of exponential $>$ spherical $>$ K-Bessel $>$ Gaussian was revealed by the nugget to sill ratio, as the smaller the ratio, the stronger the spatial dependency. The exponential model gave the best fit to the isotropic semivariogram (Figure 1).

\section{Spatial Distribution of Potential Ecological Risk Index}

Figure 2 shows the spatial distribution map of the potential ecological RI within the AEPS. The map shows that areas of the burning, dismantling and some parts of the CAs have a very high potential ecological RI. The map also shows areas as being zones with potentially lower ecological risks.

The estimation of the potential ecological risks was conducted to evaluate the degree to which soil associated with chemical pollutants might have an impact on aquatic and terrestrial organisms, including plants $[5,22]$. The ecological RIs of the AEPS account for the contamination caused by $\mathrm{Cd}, \mathrm{Cu}, \mathrm{Hg}, \mathrm{Pb}$ and $\mathrm{Zn}$, and indicate that the AEPS is considerably impacted by the contamination. Among the different areas within the AEPS, the indices show potentially high risks in the burning, dismantling, commercial, farms and areas close to water bodies, and in some parts of the residential areas.

\section{DISCUSSION}

The mean concentrations of $\mathrm{Cu}, \mathrm{Pb}$ and $\mathrm{Zn}$ were above both the optimal and action values of the Dutch and Canadian soil

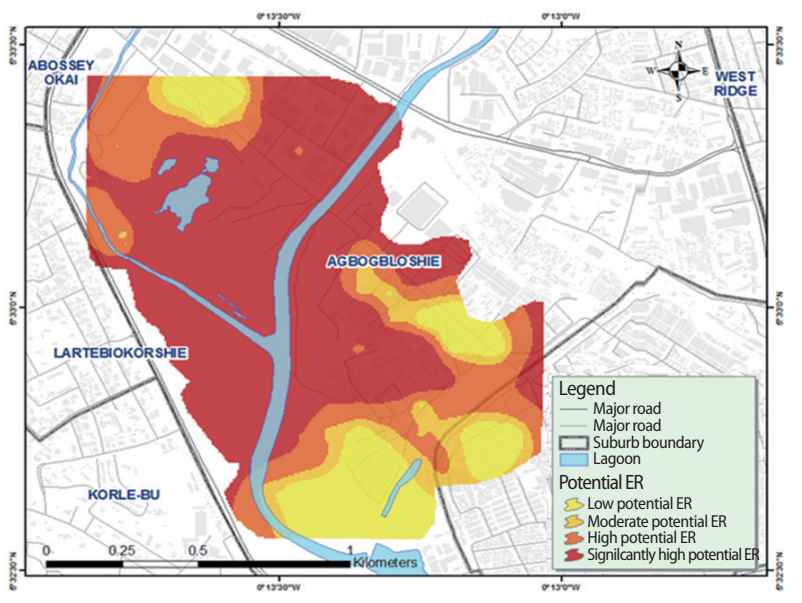

Figure 2. Potential ecological risk (ER) index map.

quality and guidance values (SQGV), and this was reflective in the metal enrichment in assessment. The significantly moderate to extremely high enrichment and mean concentrations in residential and recreational areas underscores how human activities or the proximity of these areas to the main e-waste recycling hub of burning and dismantling are linked with high levels of heavy metal enrichment or pollution. The use of ecological risk factor and the overall potential ecological risk provided empirical basis for understanding the ecological risks associated with these heavy metal concentrations in the soils in the AEPS $[16,18]$. The order of heavy metal toxicity is shown by $\mathrm{Hg}>\mathrm{Cd}>\mathrm{Pb}>\mathrm{Cu}>\mathrm{Zn}>\mathrm{Cr}$, indicating in ascending order their contribution to the potential ecological risk in the study area. Spatial randomness in the data revealed by the MI, Z-score and $p$-value and the strong spatial dependency exhibited by the nugget to sill ratio and the spatial autocorrelation imply that the measured heavy metal concentrations are affected by both anthropogenic and natural factors confirming earlier studies $[3,14]$. The ecological RI for the AEPS also represents the sensitivity of biological communities to hazardous substances $[6,15,16]$. With parts of the very high potential ecological risk zones housing cattle rearing sites, livestock, farms for vegetable production, and aquatic species in the nearby stream, these constitute current and future health risks. Of particular concern are the significantly high risk levels in the farm areas, which could negatively impact plants as the detrimental effects of heavy metals on plants and the subsequent transfer to humans and other organisms can be expected. Also, areas close to water bodies are at high ecological risk as deposits of these contaminants can seep into these water bodies, thus impacting aquatic species. Similar heavy metal contaminations impacting both terrestrial and aquatic species have been observed by the previous studies [23-25]. Organisms in the soil and plants or water bodies in the 
areas of the clinics, school, parts of the market area, and some parts of the CAs face no ecological risks.

Heavy metal contamination presents an important challenge for the AEPS and its surroundings. The focus of this paper was to study the impacts and risks posed by the heavy metals $(\mathrm{Cd}$, $\mathrm{Cr}, \mathrm{Cu}, \mathrm{Hg}, \mathrm{Pb}$ and $\mathrm{Zn}$ ) to the environment (comprising the soil, air, surface and ground water) and consequent implications for terrestrial and aquatic species. On this basis, 132 soil samples were collected, analysed, and examined for heavy metals, potential ecological risk, and the spatial extent of the risk. In general, the heavy metal concentrations measured in soils from AEPS and its environs exceeded the regulatory limits of both the Dutch and Canadian environmental agencies. In the order of $\mathrm{Hg}>\mathrm{Cd}>\mathrm{Pb}>\mathrm{Cu}>\mathrm{Zn}>\mathrm{Cr}$, the heavy metals significantly contributed to the potential ecological risk. Spatial analysis parameters, sill to nugget ratio, and MI revealed strong spatial dependency and autocorrelation, indicating the influence of both natural and anthropogenic factors as contributing to levels of heavy metals and their subsequent implication of potential ecological risk. With 59\% (98 ha), 20\% (33 ha), 8\% (14 ha) and 13\% (23 ha) of the land areas in the AEPS classified as significantly high, high, moderate, and low potential ecological risk zones, respectively, there is the need for further and more detailed studies to be conducted on the activities of informal e-waste recyclers, and implement environmentally sustainable ways to efficiently recover valuable metals from e-waste in Ghana.

\section{CONFLICT OF INTEREST}

The authors have no conflicts of interest associated with the material presented in this paper.

\section{ORCID}

Vincent Nartey Kyere http://orcid.org/0000-0002-8727-6442 James Ephraim http://orcid.org/0000-0002-5747-9193

\section{REFERENCES}

1. Asante KA, Agusa T, Biney CA, Agyekum WA, Bello M, Otsuka M, et al. Multi-trace element levels and arsenic speciation in urine of ewaste recycling workers from Agbogbloshie, Accra in Ghana. Sci Total Environ 2012;424:63-73.

2. Atiemo SM, Ofosu FG, Aboh IK, Kuranchie-Mensah H. Assessing the heavy metals contamination of surface dust from waste electrical and electronic equipment (e-waste) recycling site in Accra, Ghana. Res J Environ Earth Sci 2012;4(5):605-611.

3. Brigden K, Labunska I, Santillo D, Johnston P. Chemical contamination at e-waste recycling and disposal sites in Accra and Kor- foridua, Ghana; 2008 [cited 2017 Oct 10]. Available from: http:// www.greenpeace.org/international/Global/international/planet-2/report/2008/9/chemical-contamination-at-e-wa.pdf.

4. Wang X, Sato T, Xing B, Tao S. Health risks of heavy metals to the general public in Tianjin, China via consumption of vegetables and fish. Sci Total Environ 2005;350(1):28-37.

5. Bai J, Cui B, Chen B, Zhang K, Deng W, Gao H, et al. Spatial distribution and ecological risk assessment of heavy metals in surface sediments from a typical plateau lake wetland, China. Ecol Model 2011;222(2):301-306.

6. Hakanson L. An ecological risk index for aquatic pollution control. A sedimentological approach. Water Res 1980;14(8):975-1001.

7. Yi Y, Yang Z, Zhang S. Ecological risk assessment of heavy metals in sediment and human health risk assessment of heavy metals in fishes in the middle and lower reaches of the Yangtze River basin. Environ Pollut 2011;159(10):2575-2585.

8. Ljung K, Selinus O, Otabbong E. Metals in soils of children's urban environments in the small northern European city of Uppsala. Sci Total Environ 2006;366(2):749-759.

9. Acosta JA, Cano AF, Arocena JM, Debela F, Martínez-Martínez S. Distribution of metals in soil particle size fractions and its implication to risk assessment of playgrounds in Murcia City (Spain). Geoderma 2009;149(1):101-109.

10. Caravanos J, Clark E, Fuller R, Lambertson C. Assessing worker and environmental chemical exposure risks at an e-waste recycling and disposal site in Accra, Ghana. J Health Pollut 2011;1(1):16-25.

11. Otsuka M, Itai T, Asante KA, Muto M, Tanabe S. Trace element contamination around the e-waste recycling site at Agbogbloshie, Accra City, Ghana. Interdiscip Stud Environ Chem Environ Pollut Ecotoxicol 2012;6(6):161-167.

12. Itai T, Otsuka M, Asante KA, Muto M, Opoku-Ankomah Y, AnsaAsare OD, et al. Variation and distribution of metals and metalloids in soil/ash mixtures from Agbogbloshie e-waste recycling site in Accra, Ghana. Sci Total Environ 2014;470-471:707-716.

13. Caeiro S, Costa MH, Ramos TB, Fernandes F, Silveira N, Coimbra A, et al. Assessing heavy metal contamination in Sado Estuary sediment: an index analysis approach. Ecol Indic 2005;5(2):151-169.

14. Qingjie G, Jun D, Yunchuan X, Qingfei W, Liqiang Y. Calculating pollution indices by heavy metals in ecological geochemistry assessment and a case study in parks of Beijing. J China Univ Geosci 2008;19(3):230-241.

15. Amuno SA. Potential ecological risk of heavy metal distribution in cemetery soils. Water Air Soil Pollut 2013;224(2):1435.

16. Abrahim GM, Parker RJ. Assessment of heavy metal enrichment factors and the degree of contamination in marine sediments from Tamaki Estuary, Auckland, New Zealand. Environ Monit Assess 2008;136(1-3):227-238.

17. Duce RA, Quinn JG, Olney CE, Piotrowicz SR, Ray BJ, Wade TL. Enrichment of heavy metals and organic compounds in the surface microlayer of Narragansett Bay, Rhode Island. Science 1972;176 (4031):161-163.

18. Karageorgis AP, Katsanevakis S, Kaberi H. Use of enrichment factors for the assessment of heavy metal contamination in the sediments of Koumoundourou Lake, Greece. Water Air Soil Pollut 2009;204(1-4):243.

19. Wu YG, Xu YN, Zhang JH, Hu SH. Evaluation of ecological risk 
and primary empirical research on heavy metals in polluted soil over Xiaoqinling gold mining region, Shaanxi, China. Trans Nonferrous Met Soc China 2010;20(4):688-694.

20. Matheron G. Principles of geostatistics. Econ Geol 1963;58(8): 1246-1266.

21. Oliver MA, Webster R. Kriging: a method of interpolation for geographical information systems. Int J Geogr Inf Sys 1990;4(3):313332.

22. Wenning RJ, Ingersoll CG. Use of sediment quality guidelines and related tools for the assessment of contaminated sediments. In: Society of Environmental Toxicology and Chemistry (SETAC). Executive Summary of a SETAC Pellston Workshop; 2002 Aug 17-
22; Fairmont, MT, USA. Pensacola: SETAC Press; 2002, p. 1-44. 23. Bryan GW. The effects of heavy metals (other than mercury) on marine and estuarine organisms. Proc R Soc Lond B Biol Sci 1971; 177(1048):389-410.

24. Bryan GW, Gibbs PE. Heavy metals in the Fal estuary, Cornwall: a study of long term contamination by mining waste and its effects on estuarine organisms; 1983 [cited 2017 Oct 10]. Available from: http://plymsea.ac.uk/275/1/pdf\%20occ\%20pub\%202.pdf.

25. Dallinger R, Prosi F, Segner H, Back H. Contaminated food and uptake of heavy metals by fish: a review and a proposal for further research. Oecologia 1987;73(1):91-98 